\title{
TWO META-ANALYSES OF NONCONTACT HEALING STUDIES $^{\text {a }}$
}

\begin{abstract}
Reviews of empirical work on the efficacy of noncontact healing have found that interceding on behalf of patients through prayer or by adopting various practices that incorporate an intention to heal can have some positive effect upon their wellbeing. However, reviewers have also raised concerns about study quality and the diversity of healing approaches adopted, which makes the findings difficult to interpret. Some of these concerns can be addressed by adopting a standardised approach based on the double-blind randomised controlled clinical trial, and a recent review restricted to such studies has reported a combined effect size of $.40(p<.001)$. However, the studies in this review involve human participants for whom there can be no guarantee that control patients are not beneficiaries of healing intentions from friends, family or their own religious groups. We proposed to address this by reviewing healing studies that involved biological systems other than 'whole' humans (i.e. to include animal and plant work but also work involving human biological matter such as blood samples or cell cultures), which are less susceptible to placebo and expectancy effects and also allow for more circumscribed outcome measures. Secondly, doubts have been cast concerning the legitimacy of some of the work included in previous reviews so we planned to conduct an updated review that excluded that work. For phase 1, 49 non-whole human studies from 34 papers were eligible for review. The combined effect size weighted by sample size yielded a highly significant $r$ of .258. However the effect sizes in the database were heterogeneous, and outcomes correlated with blind ratings of study quality. When restricted to studies that met minimum quality thresholds, the remaining 22 studies gave a reduced but still significant weighted $\mathrm{r}$ of .115. For phase 2, 57 whole human studies across 56 papers were eligible for review. When combined, these studies yielded a small effect size of $r=.203$ that was also significant. This database was also heterogeneous, and outcomes were correlated with methodological quality ratings. However, when restricted to studies that met threshold quality levels the weighted effect size for the 27 surviving studies increased to $r=.224$. Taken together these results suggest that subjects in the active condition exhibit a significant improvement in wellbeing relative to control subjects under circumstances that do not seem to be susceptible to placebo and expectancy effects. Findings with the whole human database gave a smaller mean effect size but this was still significant and suggests that the effect is not dependent upon the previous inclusion of suspect studies and is robust enough to accommodate some high profile failures to replicate. Both databases show problems with heterogeneity and with study quality and recommendations are made for necessary standards for future replication attempts.
\end{abstract}

\section{INTRODUCTION}

The supposed linkage between religious beliefs and practices and health has long been of interest to psychologists since it provides suggestive evidence for a connection between psycho-spiritual factors and physical wellbeing. ${ }^{1,2}$ This research is an extension of conventional accounts of the health benefits of religiosity and/or spirituality that supposes that they are mediated by cognitive and behavioural differences, with those expressing a religious faith tending to be more optimistic and resilient, to believe that the physical world is essentially orderly and meaningful, to engage in healthy behaviours such as

\footnotetext{
${ }^{a}$ We should like to thank the Confederation of Healing Organisations for their kind support of this project
} 
regular exercise or meditation, and to avoid unhealthy behaviours such as drug and alcohol abuse and promiscuous or risky sex (for reviews see Fontana ${ }^{3}$ and Koenig, King \& Carson $^{4}$ ). More intriguingly, a number of reviews of the efficacy of healing, ${ }^{5,6,7,8}$ have found that interceding on behalf of patients through prayer or by adopting various practices that incorporate an intention to heal can have some positive effect upon their wellbeing. However, these reviewers also raised concerns about study quality and the diversity of healing approaches adopted in the studies under review — ranging from techniques that usually involve close physical proximity between practitioner and patient, such as therapeutic touch and Reiki healing, through to techniques that work at a distance, such as psychic healing or intercessionary prayer to a higher being — and this makes the findings difficult to interpret since in some cases the beneficial effects could be attributable to placebo effects or to the consequences of general lifestyle changes that are involved in holistic approaches to medicine. The diversity of approaches included under the rubric of healing also presents problems in explaining the observed effects, since there is so little common ground that it is difficult to conceive of a mechanism that they might all share.

Some of these concerns can be addressed by conducting double-blind randomised controlled clinical trials. These entail the random allocation of participants (or patients) to either a treatment or control condition so as to control for selection bias (or alternatively participants are matched on the basis of other variables that are thought to affect the prognosis of their health condition, such as age, gender, comorbidity, and so on), with patients and attending physicians remaining blind to the allocation so as to control for placebo improvements. Such a design has been described by Astin, Harkness and Ernst ${ }^{9}$ as meeting minimum standards for research quality.

Perhaps the first study (and certainly the most influential) that met these criteria is Byrd's ${ }^{10}$ consideration of the effects of intercessory Judeo-Christian prayer with a population of 393 coronary care unit patients. Participants were randomly assigned on a double blind basis to either a control or a prayer group on admission to the unit. Each participant in the prayer group was assigned to between 3 and 7 intercessors, who were given the patient's name, diagnosis, general condition and updates of their condition throughout the trial (but not sufficient information to be able to trace the patient). The intercessors themselves were from a variety of Protestant and Roman Catholic churches, the only conditions to becoming an intercessor were that they had to be 'born again' according to the Gospel of John 3:3 and that they should "lead an active Christian life as manifested by daily devotional prayer and active Christian fellowship with a local church" (p. 827). Intercessory prayer was conducted daily, and involved asking for a "rapid recovery, and for preventions of complications and death, in addition to other areas of prayer they believed to be beneficial to the patient" (p. 827). Byrd found that the prayer group presented with significantly fewer cases of pneumonia, congestive heart failure, intubation/ventilation, cardio pulmonary arrest and significantly less need for antibiotics and diuretics. Significantly more participants in the prayer group also showed a 'good' hospital course, i.e. "no new diagnoses problems or 
therapies were recorded for the patient or if events occurred that only minimally increased the patient's morbidity or risk of death" (p. 828).

Other well-controlled studies have also reported positive outcomes. For example, Sicher, Targ, Moore and Smith ${ }^{11}$ conducted a study into distance healing using a population of people with advanced AIDs. Forty participants were pair matched by age, CD4+ count and number of AIDs defining diseases (ADDs), before being randomly assigned to either the distance healing or control group. Four Initial measurements were taken: CD4+ count, psychological distress (measured using the Profile of Mood States), physical symptoms (measured using the Whaler Physical Symptoms Inventory) and quality of life (measured using the Medical Outcomes Survey for HIV). These same measurements were also taken after the 10 week treatment period and 12-14 weeks later at the follow-up stage. During the study period, participants also reported doctor's visits, hospitalisation, illness recovery and onset of new illnesses. Rather than working with traditional Christian groups, Sicher and colleagues recruited distance healing practitioners from different traditions or schools, but all with a minimum of 5 years regular ongoing healing practice, previous experience of distance healing with at least 10 patients, and previous experience of distance healing for patients with AIDS. Each practitioner treated 5 subjects for 6 hours in total (one hour daily for 6 days). Each participant received healing from 10 different practitioners. Sicher et al. found that during the 6 months of the study patients in the treatment condition experienced significantly fewer doctor's visits, hospitalisations, and new ADDs, as well as significantly shorter periods of hospitalisation, significantly lower severity of illness and significantly improved mood. However, no significant differences in physical symptoms or quality of life were found between the groups. Despite the marked differences in procedure (including the populations from which healers were drawn and the method by which healing was delivered) the positive findings have been regarded as a successful replication of Byrd (but see also Bronson ${ }^{12}$ for suggestions that the authors capitalised on data mining).

Some of this high quality research has been summarised by Astin et al., ${ }^{9}$ who restricted their review to only those clinical studies that included: random assignment of participants to conditions; a placebo control condition; publication in full in peer reviewed journal; and use of participants who suffered from any medical condition (thus excluding research involving direct mental interactions with living systems [DMILS] and staring detection studies such as those summarised by Schmidt, Schneider, Utts \& Walach ${ }^{13}$, which reported significant effects of intention upon electrodermal activity in healthy participants). Astin et al. ${ }^{9}$ identified 23 studies that met these criteria, collectively involving 2,774 participants, which produced the predicted improvement in condition with a combined effect size of $.40(p<.001)$. Among these studies, 13 (57\%) showed a positive treatment effect, 9 showed no effect, and 1 showed a negative effect. Despite remaining concerns about the heterogeneity of the database and methodological limitations with some studies, the authors were able to conclude that the evidence was sufficiently strong to warrant further study. 
A later review by Astin $^{14}$ was restricted to prayer studies and consisted of 14 studies with a combined 2,448 participants. These were mainly drawn from the earlier review (but with some additions, such as Abbott et al., 2001) so does not provide much new information. Again the outcome was positive, with 6 studies (43\%) showing a positive treatment effect and the database generating an overall effect size of 30 . This is somewhat lower than the effect size reported when studies of therapeutic touch are included and other reviews have suggested that this approach may of particular interest. ${ }^{15}$ It should be noted that Ernst also provided an update, consisting of 17 studies published after his 2000 review, and found that their outcomes "collectively... shift the weight of the evidence against the notion that distant healing is more than a placebo" (p. 241). ${ }^{16}$

\section{Rationale for the current study}

Despite incorporating randomised control blinded studies, the studies included in Astin et al.'s review ${ }^{9}$ are still susceptible to counter explanations as a consequence of their inability to create an appropriate control condition (there can be no guarantee that control patients are not beneficiaries of healing intentions from friends, family or their own religious groups, for example). Additionally, putative relationships between healing intention and wellbeing might be obscured by reliance on relatively crude health outcomes (such as reduced depression scores) that themselves are open to influence from other mechanisms such as placebo and expectancy effects and are sensitive to other environmental and physical stressors that can vary over the course of a study. We would argue that related research that focuses on effects upon simpler biological systems than 'whole humans' (such as growth of bacterium cultures, haemolysis of blood samples, or plant growth) would be less sensitive to the effects of such confounding variables and are likely to allow for 'cleaner' control groups — plants seem unlikely to have expectancies concerning participation in a healing study, to have relatives sending them healing intentions, and give rise to more straightforward and pre-specifiable wellbeing indicators. We therefore planned to conduct a quantitative review of healing studies that involve biological systems other than 'whole' humans. Although some of this research has been reviewed previously (especially by Benor ${ }^{5}$ and Braud $^{17}$ ), these do

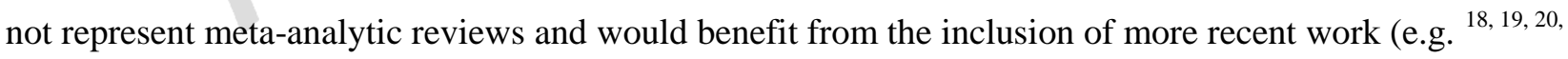
${ }^{21,22}$ ). We proposed to blind code such studies for methodological quality as well as other parameters so as to determine (i) whether there is an overall effect that cannot be explained in terms of Type I error, methodological flaws or experimenter effects; and (ii) whether effect sizes covary with other properties of the study design in a manner that might elucidate the mechanism of such effects.

Secondly, since Astin's reviews have been published, serious doubts have been cast concerning the legitimacy of work conducted by Daniel P. Wirth (see Flamm ${ }^{23}$; Solfvin, Leskowitz \& Benor ${ }^{24}$ ) such that it would be unsafe to base conclusions on data that he has provided - Wirth contributed 5 studies to Astin et al.'s review, ${ }^{9}$ one study to Astin's review, ${ }^{14}$ and 5 studies to Daley's review. ${ }^{15}$ There is therefore a need 
to revisit these meta-analytic reviews of research with 'whole' humans but with Wirth's body of work removed. There has also been a 'second wave' of replication attempts that have not been included in reviews to date; some of these have confirmed predictions (e.g. Krukoff et al. ${ }^{25}$; Leibovici ${ }^{26}$ ) but there are also some high profile failures to replicate (e.g., Aviles et al. ${ }^{27}$; Benson et al. ${ }^{28}$; Krukoff et al. ${ }^{29}$ ). To our knowledge there has been no systematic meta-analytic review that has included these studies and in our view an updated and expanded review would be timely. Therefore phase 2 of the current project consisted of a quantitative review of healing studies involving 'whole' humans in a manner that addresses the shortcomings identified above.

\section{METHOD}

\section{Identifying qualifying studies}

A comprehensive literature search was conducted by one of the authors (CS) to identify studies of distant healing using the following databases: Swetswise, ASSIA, Psych-NET, Web of Science, Cochrane Library, British Nursing Index, Cinahl Full Text, and Informaworld. Care was taken to ensure that nursing and medical journals were included in the search as well as those covering research in the social sciences. Search terms used were determined from a review of previous reviews and included the following: "Spiritual healing", "Distance Healing", "Noetic Healing", "Intercessory Prayer", "Laying on of hands", “Therapeutic Touch", "Johrei”, and "Reiki". "Healing" was not used as a search term in order to avoid an excess of pharmaceutical research. For phase 1 this search was restricted by the inclusion of the qualifiers “Animals", "Plants", "Yeast", "Bacteria", and "Cells". The papers resulting from these searches were then read by CS, who decided which studies met the inclusion criteria outlined below. References lists of qualifying papers were then searched to identify further relevant studies, and this process was repeated until no new papers were identified. To minimise the file drawer effect, authors of included papers were also contacted to request details of any qualifying studies which were not listed in our database.

\section{Inclusion/Exclusion criteria}

Only studies in English were eligible for inclusion in this review. All studies must have examined the effects upon a biological system of the explicit intention to improve the wellbeing of that target system. Thus studies exploring the effects of intention upon physical systems or random number generators as their targets ${ }^{30,31}$ were excluded, as were studies which looked at the effects of mental influence on movement of animals. ${ }^{32}$ Similarly remote staring and DMILS studies were excluded on the grounds that they did not incorporate an intention to heal. The healing conducted must not involve direct touching, so as to be able to exclude the beneficial effects of contact/massage therapy. ${ }^{33,34,35}$ Papers that did not provide enough information of their methodology to allow for quality assessment were excluded as were studies 
that did not include a comparison condition (typically those involving only pre-post comparisons) and those that did not provide sufficient data to allow for an effect size calculation. To avoid systematic bias, where studies were reported as nonsignificant with no further statistical information they were coded as having an effect size of zero.

\section{Quality assessment}

In order to produce methodological quality assessments, CS produced versions of the method section for each qualifying study that excluded all information that might identify the researchers or give an indication of the study outcome. Each paper was allocated a code number and these numbers were randomised so that discrete studies in the same experimental series would not have consecutive code numbers and so would not be assessed one after another. Copies of these edited papers were provided in batches for judges in pdf format.

Three judges ${ }^{\mathrm{b}}$ independently rated the studies for methodological quality using an adapted version of part 3 of the SIGN50 Methodology Checklist $2 .{ }^{36}$ The SIGN50 scale was originally created in 2002 by the Scottish Intercollegiate Guidelines Network, which is responsible for producing evidence-based clinical practice guidelines for the Scottish National Health Service, as a tool to appraise the quality of clinical research. Judges are asked to rate the study along a number of dimensions using the following rating options: "well covered"; "adequately addressed"; "poorly addressed"; "not addressed"; "not reported"; and "not applicable". The more rigorous the methods used, the higher the rating given for that item. For example, for item 1.2 "The assignment of subjects to treatment groups is randomised", allocation by date of birth or by patient number were not considered to be true randomisation processes and so studies using such methods were given a rating of "poorly addressed"; randomisation methods using hand shuffled cards or hand rolled die, whilst somewhat more random are still subject to bias and were therefore be rated as "adequately addressed"; and truly random methods using a random number generator or published tables of random numbers are rated as "well covered". In the original scale, the "not reported" option was defined as "mentioned, but insufficient detail to allow assessment to be made" and the "not addressed" option defined as "not mentioned, or indicates that this aspect of study design was ignored". During the pilot phase, judges felt that it would make more sense if the definitions of these two items were swapped because "not reported" suggested that that aspect of the methodology had been left out of the report altogether and that "not addressed" suggested that that aspect had been referred to but not effectively dealt with.

\footnotetext{
${ }^{\mathrm{b}}$ We should like to thank Sophie Drennan and Jacqueline Stone for their contribution as judges in phase 1, and Sophie Ridgway and David Saunders for their contribution as judges in phase 2. CR acted as a judge in both phases and was not involved in other aspects of the study until judging was completed.
} 
Following pilot work, some of the items were modified to tailor them to current needs. We removed item 1.3, "An adequate concealment method is used" because concealment was covered under blinding (see below), and item 1.10 "Where the study is carried out at more than one site, results are comparable for all sites" because it was not applicable. Item 1.4 " Subjects and investigators are kept 'blind' about treatment allocation" was expanded to give three separate items that better reflected levels of blinding: "subjects are kept blind about treatment allocation", "investigators are kept blind about treatment allocation" and "data analysts are kept blind about treatment allocation". The following items were also added to the scale;

- "Controls in place for extraneous variables" (item 1.8).

- "Healers applied a consistent method of treatment" (item 1.9).

- "Rationale given for selection of healers" (item 1.10).

- "Controls in place to prevent Healers affecting participants/targets by conventional means" (item $1.12)$.

Judges were finally asked to give a rating out of 10 to represent the overall methodological quality of each study.

\section{Calculating a common effect size}

The main outcome statistics were converted to the common effect size, $r^{c}$, by CS before judges quality ratings were collected so as to avoid any chance of bias influencing the conversions. Where no main outcome measure was identified, measures were selected that were most similar to measures used in other studies. If no such measure was utilised within a study, then the measure selected was the one which seemed most relevant to the condition being treated and which reported the most statistical information to allow for conversion, such as the number of participants in each group and the degrees of freedom. The statistics were converted by hand using formulae provided by Clark-Carter. ${ }^{37}$ Analyses were checked by CR once all judging had been completed.

\section{ANALYSis (PHASE 1)}

Initially, 156 non-whole human sample studies were identified from 95 papers. Of these, 107 studies from 61 papers had to be eliminated from the meta analysis as they were either reviews of other studies, reported too little information or did not fit with the above inclusion criteria. Thus 49 studies from 34

\footnotetext{
${ }^{c}$ Pearson's $r$ is a common effect size measure where one is interested in identifying the amount of variance (e.g. in health outcomes) that can be explained by the intervention measure. It was preferred here because values are readily comprehensible by those familiar with correlational analysis, with values typically fallin in the range -1 to +1 and values close to zero indicating no relationship. $\mathrm{r}$ values can be converted to $\mathrm{z}$ scores using $\mathrm{r}=\mathrm{z} /(\operatorname{root} \mathrm{N})$.
} 
papers were eligible for review. Effect sizes for these studies are illustrated in Figure 1. The combined effect size for the non-whole human studies weighted by sample size yielded an $r$ of $.258\left(\mathrm{CI}_{95}=.239\right.$ to .278), which is significant at the $5 \%$ level.

However, the effect sizes in the database are significantly heterogeneous $\left(\chi^{2}[48]=487.8\right)$, and 10 'outliers' need to be cropped in order to reduce to non-significance, which reduces the weighted mean effect size for the cropped studies to $r=.204$, although this remains significant $\left(\mathrm{CI}_{95}=.172\right.$ to .236$)$.

\section{Effect size \& quality estimates}

In order to explore causes of variance in study outcomes, effect sizes were correlated against independent judges' average ratings for various quality dimensions. This would evaluate the extent to which observed effects might be attributable to methodological flaws. Given the limited range for quality ratings, nonparametric correlations were calculated, and these are given in Table 1. A number of negative correlations can be observed that are consistent with an explanation in terms of methodological artefact; this association is significant for randomisation method and suggestive for double blinding, control of extraneous variables and clear specification of planned analyses. However, it should be noted that the average quality rating for these studies is low (mean $=4.3 / 10, S D=1.9$ ) such that even relatively highly rated studies may still suffer from some methodological weaknesses.

To evaluate whether these weaknesses could account for the observed effects, we identified those studies that were rated as "well covered or "adequately addressed" on all the following parameters: the assignment of subjects to treatment groups is randomised; investigators are kept 'blind' about treatment allocation; the treatment and control groups are similar at the start of the trial; the only difference between the groups is the treatment under investigation; controls in place for extraneous variables; and controls in place to prevent healers affecting participants/targets by conventional means. The 22 studies that met these criteria gave a weighted effect size, $r=.115$, which remains significantly different from the null value of zero $\left(\mathrm{CI}_{95}=.090\right.$ to .141$)$.

TABLE 1: SPEARMAN RHO CORRELATIONS BETWEEN STUDY WEIGHTED EFFECT SIZES AND AVERAGE QUALITY RATINGS FROM INDEPENDENT JUDGES FOR NON-WHOLE HUMAN STUDIES

\section{Quality criterion}

The assignment of subjects to treatment groups is randomised

Investigators are kept 'blind' about treatment allocation

Data analysts are kept 'blind' about treatment allocation
Rho

$-.413$

$-.281$

$-.239$ $p$

.004

.055

.106 
The treatment and control groups are similar at the start of the trial

The only difference between the groups is the treatment under investigation

Controls in place for extraneous variables

Healers applied a consistent method of treatment

Controls in place to prevent healers affecting participants/targets by

conventional means

All relevant outcomes are measured in a standard, objective, valid and

reliable way

There is no scope within the design for optional stopping or otherwise

capitalising on chance variation in the outcome

Analyses are clearly pre-planned and corrected for multiple analyses where appropriate

Overall quality rating

\section{Blocking studies by target system}

To further explore causes of variance in outcome, studies were blocked by target system type. Three categories had sufficient members for separate analysis: animal, plant and in vitro studies. The largest category consisted of 22 in vitro studies (cell cultures, tissue samples). These gave a weighted mean effect size, $r=.342\left(\mathrm{CI}_{95}=.319\right.$ to .363$)$. The sample was significantly heterogeneous, $\chi^{2}=271.19, p<.001$, and 11 outliers had to be removed to reduce this to $\chi^{2}=17.78 . p>.05$. The mean weighted effect sized for the cropped sample reduces to $r=.248$ but remains significant $\left(\mathrm{CI}_{95}=.167\right.$ to .325$)$.

Non-human animals (e.g., rats, mice, bush babies) were the subjects in 11 studies. These studies produced a significant weighted mean effect size of $r=.277\left(\mathrm{CI}_{95}=.160\right.$ to .386$)$. This sample was marginally heterogeneous, $\chi^{2}=18.92, \mathrm{p}<.05$ (removing 1 outlier gives $p>.05$ ). The mean weighted effect sized for the cropped sample reduces slightly to $r=.246$ but again remains significant $\left(\mathrm{CI}_{95}=.123\right.$ to .361$)$.

For 16 studies the target systems were plants or seeds. These had a mean quality rating of just 3.22, and also gave a significant weighted mean effect size, $r=.125\left(\mathrm{CI}_{95}=.098\right.$ to .153$)$. This sample was also significantly heterogeneous, $\chi^{2}=129.45, p<.001$. Removing 3 outliers gives $\left.\chi^{2}=19.14, p>.05\right)$. The 
Two Meta-Analyses of Noncontact Healing Studies

mean weighted effect sized for the cropped sample increases to $r=.197$ and is significant $\left(\mathrm{CI}_{95}=.156\right.$ to .238). The weighted average effect sizes for the cropped in vitro and nonhuman animal studies falls outside this confidence interval, indicating that outcomes for the plant studies are significantly different.

\section{Publication bias}

To evaluate whether the observed effect sizes might be affected by publication/availability bias, a funnel plot was constructed (Figure 1). Although the pattern is distorted somewhat by researchers' greater tendency to give less statistical detail when outcomes were "nonsignificant" (in which case effect sizes were recorded here as zero to avoid loss of null data), it is clear that the plot is highly asymmetrical, with expected studies reporting null outcomes and (particularly) reversed effects being absent, which is suggestive of a publication bias. In order to estimate the number of unpublished non-significant studies that would be needed to render the database non-significant overall, Rosenthal's failsafe $\mathrm{N}$ was calculated. ${ }^{39}$ This gives a value of $46,196^{\mathrm{d}}$ where the critical number of studies is 240 , suggesting that the file drawer effect alone cannot account for the observed results.

Figure 1: Funnel plot of effect size by log N for non-whole human sample

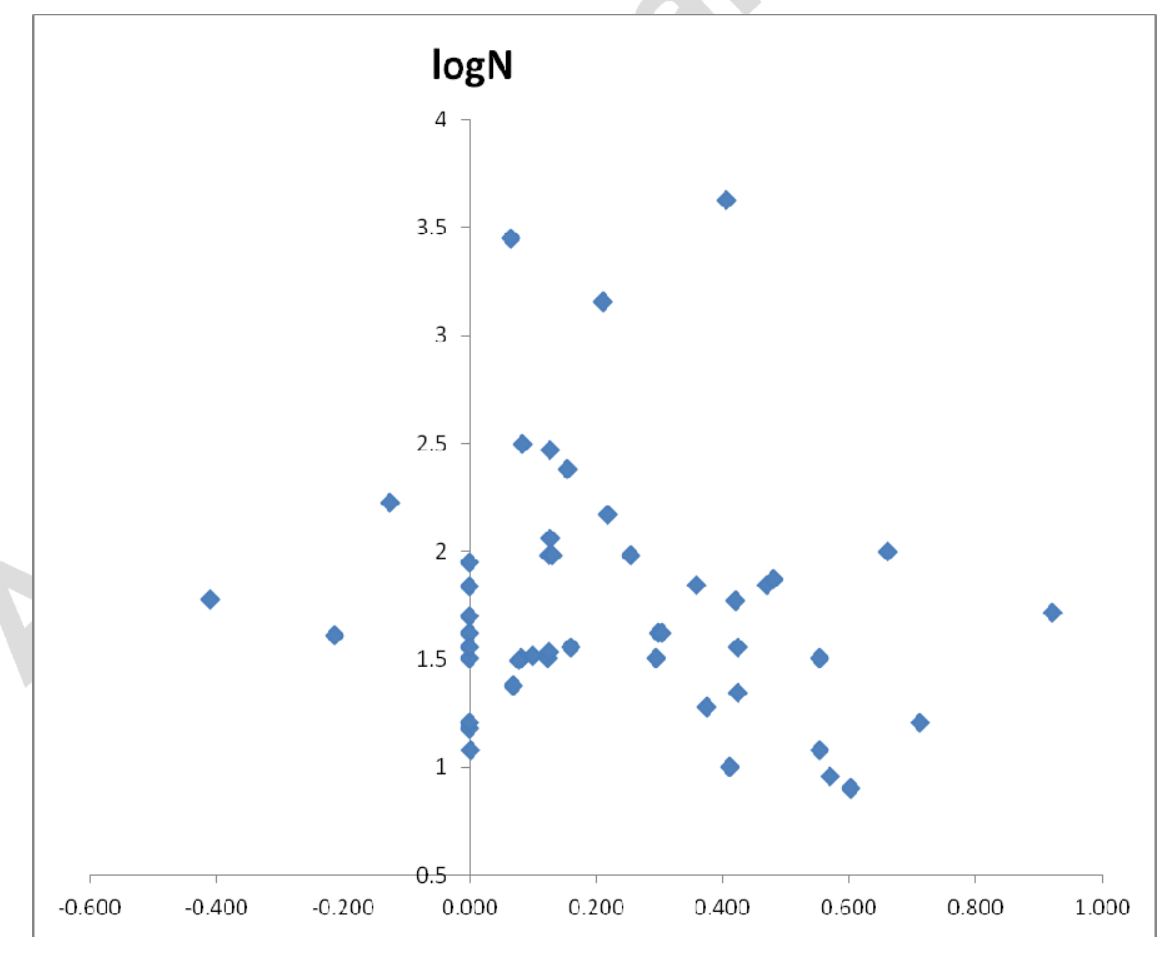

\footnotetext{
${ }^{\mathrm{d}}$ Three studies whose sample sizes were substantially larger than the remaining studies were omitted so as not to skew these estimates.
} 


\section{ANALYSIS (PHASE 2)}

For the whole human meta-analysis, 182 studies were identified initially from 180 papers, of which 121 studies from 121 papers had to be eliminated from the meta analysis as they were either reviews of other studies, reported too little information or did not fit with the above inclusion criteria, leaving 57 studies across 56 papers that were eligible for review. Weighted effect sizes were calculated and these are illustrated in Figure 2. When combined, these studies yielded a small effect size of $r=.203$ that was significant $\left(\mathrm{CI}_{95}=.180\right.$ to .232$)$. As with the non-human meta-analysis, this database is significantly heterogeneous $\left(\chi^{2}=754.7\right) ; 11$ outliers need to be removed to reduce this non-significance at $p>.05$. The mean weighted effect sized for the cropped sample reduces slightly to $r=.193$ but remains significant $\left(\mathrm{CI}_{95}=.151\right.$ to .241$)$.

\section{Effect size \& quality estimates}

Study outcomes for whole human studies were correlated against independent judges' quality ratings, and these are given in Table 2. Of most concern is that judges' overall ratings of study quality are negatively correlated with study outcome, suggesting that the observed effect might — at least in part be attributable to methodological shortcomings ( $\mathrm{rho}=-.253, \mathrm{p}=.058)$. Of the various quality dimensions, 11 of 13 also give negative correlations with study outcome, of which the strongest are suggestive associations with control of extraneous variables, rationale for healer selection, and explicit pre-planning of primary analyses, and a significant association with randomisation.

In order to explore whether these factors could account for the observed effects, a subsample of methodologically superior studies was identified using the quality criteria described for phase 1 . Of the original 57 studies, 27 met these threshold standards, giving a slightly larger weighted effect size, $r=.224$ $\left(\mathrm{CI}_{95}=.194\right.$ to .253$)$.

TABLE 1: SPEARMAN RHO CORRELATIONS BETWEEN STUDY WEIGHTED EFFECT SIZES AND AVERAGE QUALITY RATINGS FROM INDEPENDENT JUDGES FOR NON-WHOLEHUMAN STUDIES

Quality criterion

The assignment of subjects to treatment groups is randomised

Participants kept 'blind' about treatment allocation

Investigators are kept 'blind' about treatment allocation
Rho

$-.150$

$-.078$
$\mathrm{P}$

.012

.264

.566 
Two Meta-Analyses of Noncontact Healing Studies

Data analysts are kept 'blind' about treatment allocation

Controls in place for extraneous variables

Healers applied a consistent method of treatment

Rationale given for selection of healers

Controls in place to prevent healers affecting participants/targets by conventional means

All relevant outcomes are measured in a standard, objective, valid and reliable way

There is no scope within the design for optional stopping or otherwise capitalising on chance variation in the outcome

Analyses are clearly pre-planned and correct for multiple analyses where appropriate

Overall quality rating
$-.165$

$-.151$

$-.092$

.498

$-.233$

.081

.017

.902

.221

.262

.075

$-.187$

.164

.089

.508

$-.173$

.198

$-.233$

.081

$-.253$

\section{Blocking studies by healing method}

Whole human studies could not be blocked by target system because the conditions being treated were too varied or were poorly specified. Instead we categorised studies according to the reported healing method used, with four categories having sufficient members for separate analysis: intercessionary prayer, therapeutic touch, Reiki or Johrei, and unspecified/other. The largest category consisted of 20 unspecified /other studies, which had a mean quality rating of 5.94 and gave a weighted mean effect size, $r=.163$ $\left(\mathrm{CI}_{95}=.105\right.$ to .219$)$. The sample was significantly heterogeneous, $\chi^{2}=57.34, p<.001$; removal of 3 outliers reduces this to nonsignificance, with a mean effect size for the cropped sample that increases to $r$ $=.193\left(\mathrm{CI}_{95}=.115\right.$ to .267$)$. Therapeutic touch was implemented in 19 studies (mean quality rating: 5.25), giving a weighted mean effect size, $r=.371\left(\mathrm{CI}_{95}=.308\right.$ to .430$)$. This sample was also significantly heterogeneous, $\chi^{2}=217.58, p<.001$; removal of 3 outliers reduces $\chi^{2}$ to $19.39, p>.05$, giving a reduced effect size for the cropped sample of $r=.203\left(\mathrm{CI}_{95}=.128\right.$ to .276). Eleven studies incorporated intercessionary prayer, giving the smallest weighted mean effect size, $r=.173\left(\mathrm{CI}_{95}=.141\right.$ to .201$)$. This sample was also significantly heterogeneous, $\chi^{2}=446.47, \mathrm{p}<.001 ; 5$ outliers need to be removed to 
reduce this to nonsignificance, and the cropped sample gives a reduced effect size that remains significant, $r=.138\left(\mathrm{CI}_{95}=.041\right.$ to .233$)$. The smallest category consisted of 7 Reiki or Johrei studies, which gave a weighted mean effect size, $r=.320\left(\mathrm{CI}_{95}=.187\right.$ to .442$)$. This sample was also significantly heterogeneous, $\chi^{2}=33.36, p<.001$; removal of 1 outlier reduces $\chi^{2}$ to $8.85, p>.05$, and results in a reduced effect size, $r=.224\left(\mathrm{CI}_{95}=.077\right.$ to .362$)$.

\section{Publication bias}

A more extreme pattern is evident in the funnel plot for whole human studies (Figure 2) than we saw for the meta analysis of nonwhole human studies (Figure 1), with the distribution affected by there being no null or reversed studies that reported effect size outcomes. Nevertheless it is clear that the plot is suggestive of a publication/availability bias. Rosenthal's failsafe $\mathrm{N}$ gave a value of 103,497 unpublished null studies needed to reduce the effect to non-significance where the critical number of studies is 255 , again suggesting that the file drawer effect alone cannot account for the observed results.

Figure 2: Funnel plot of effect size by log $N$ for whole human sample

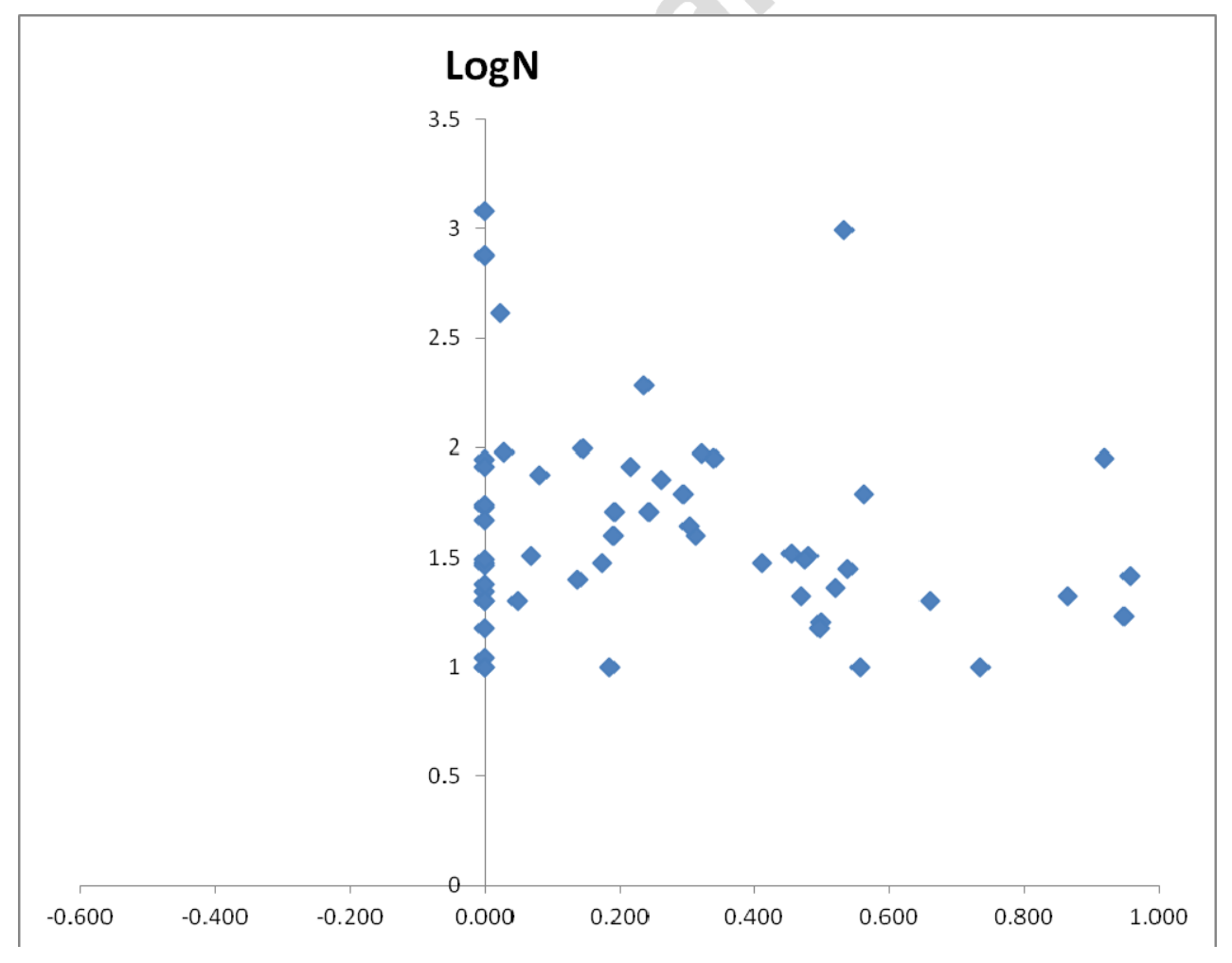




\section{DISCUSSION}

We proposed to conduct a meta-analysis of distant healing studies that involved non-whole human target systems in order to ensure a clearer distinction between active and control conditions, given that studies involving patients as subjects are likely to involve 'control' subjects who still benefit from the healing intentions from friends, family or their own religious groups. We also had concerns about the inability to control for the effects of placebo and expectancy, since participants in control conditions tend to presume they are in the active condition and so might experience placebo improvements in a manner that tends to reduce the difference between active and control conditions. These concerns can be addressed by the use of animal and tissue samples that presumably do not have expectancies about the effects of treatment or have communities of peers sending them positive intentions for their wellbeing. The combined weighted effect size for the non-whole human studies gave a weighted $r$ for the heterogeneous sample of .204, which indicates that those allocated to active healing conditions achieved better wellbeing outcomes than did those allocated to comparison conditions. Interpretation or this highly significant effect is not straightforward given that overall quality ratings were relatively low (mean $=4.3 / 10$ ), and study outcomes were significantly correlated with judges ratings of the quality dimension of randomisation, and suggestively so with investigator blinding, control of extraneous variables, and preplanning of reported analyses. However, when analysis was restricted to those studies that were rated as "well covered" or "adequately addressed" for key quality dimensions, the subsequent database still gave a significant weighted effect, $r=.115\left(\mathrm{CI}_{95}=.090\right.$ to .141$)$. This suggests to us that further research is warranted but that research must meet methodological quality standards, particularly for aspects identified in Table 1 .

We also had concerns that previous meta-analytic reviews ${ }^{9,14,15}$ had included work conducted by Daniel P. Wirth that has since been discredited ${ }^{23,24}$ and so we conducted an updated whole human analysis that omitted these studies and also included more recent publications. ${ }^{25,26,27,28,29}$ The resulting combined effect size for the homogeneous sample was small, with $r=.203$, but significant $\left(\mathrm{CI}_{95}=.180\right.$ to .232$)$. As with the Phase 1 analysis, there are quality issues here with respect to investigator blinding, control of extraneous variables, and preplanning of reported analyses, but again when these are addressed by selecting only those studies that are rated as "well covered" or "adequately addressed" with respect to key quality dimensions, the surviving studies still give rise to a significant weighted effect size, $r=.115\left(\mathrm{CI}_{95}=\right.$ .090 to .141$)$.

Both databases included blocking of studies by type and this suggested that some approaches had been more successful than others. For non-whole human research, similar effects were observed for nonhuman animals and in vitro samples, with the effect for plant studies being significantly lower. This may be a function of the complexity of the target system to be affected. For whole human studies the largest effects were associated with Reiki and Johrei interventions followed by therapeutic touch, then unspecified 
healing, although effects were relatively similar. The outcome for prayer studies was somewhat (though not significantly) lower, giving the smallest effect size for any subsample. This is consistent with Astin's ${ }^{14}$ earlier summary which found that prayer studies were less successful than therapeutic touch studies; it also reflects recent large scale failures to capture effects of distant prayer. ${ }^{28}$ It is possible that more proximal noncontact healing studies still afford some opportunities for blinds to be broken so that beneficial effects could be attributed to expectancy (although some studies are very impressive in the lengths to which they go in order to ensure that sham treatments are indistinguishable from active treatments). Alternatively, we might argue that prayer studies could take more care in ensuring that the healers they recruit constitute a homogeneous group that reliably applies a consistent method of healing; often the prayer groups are quite eclectic and little effort is made to ensure that standard practices are adhered to (Jonas has made similar observations). ${ }^{38}$

It remains difficult to draw unequivocal conclusions based on this analysis because of the clear implication from the funnel plots that there exist missing studies. This combined with some associations between outcomes and quality parameters blunts our confidence that we are deescribing genuine noncontact healing effects. This will not be resolved by reanalysis and debate but rather by the execution and publication of further randomised controlled trials that explore this putative phenomenon. Findings are, in our view, sufficiently promising to justify that effort, and we would encourage colleagues to conduct such replications. With the design of those replications in mind we make the following recommendations:

- Have a clearly circumscribed healee population with explicit inclusion/exclusion criteria

- If healees are randomly allocated to conditions rather than matched for potential confounds (such as co-morbid conditions) then researchers should measure and report any significant differences in demographic data that could impact on the illness or its treatment

- All personnel who interact with healees must be blind to condition allocation

- Researchers should state explicit criteria for the appointment of healers and intercessors that is related to the target population/illness (i.e. they should have experience of working successfully with that condition or should be able to show that previous success should generalise to the current situation)

- Homogeneity of approach across healers should be ensured through the production of explicit instruction and some attempt made to verify that this is adhered to.

- Researchers should ensure that instruction given to healers regarding desired outcomes reflects the wellbeing factors that are actually measured in the course of the study

- Researchers should ensure that actors in the sham condition closely mimic behaviours used by healers in the active condition but precluding 'inadvertent' healing effects by using actors who have no prior healing experience and who are prevented from developing positive thoughts 
Two Meta-Analyses of Noncontact Healing Studies

toward the healee (for example by having them complete mental arithmetic tasks). Interactions should be recorded to enable checks for perceptible differences between experimental and sham conditions.

- Clear descriptions should be given of precautions to prevent normal communication with patients that could affect blindness, and interactions should be monitored to ensure no facility for normal communication

- Primary outcomes should be pre-specified; where multiple dependent measures are taken these should be reported in the form of an appropriate omnibus tests (e.g. MANOVA, multiple linear regression) before individual variable tests to avoid concerns over 'cherry picking'

- Statistic effect sizes should be reported as well as p-values, and some indication given that study sizes have been designed to have sufficient power to detect the putative effect

- We had a poor response to requests for information about unpublished studies and so these are likely to be underrepresented in this analysis. We would recommend that a repository is established an that researchers are encouraged to register studies with it at the design stage.

\section{REFERENCES}

${ }^{1}$ McCullough, M.E., Hoyt, W. T., Larson, D. B., Koenig, H. G., \& Thoresen, C. E. (2000). Religious involvement and mortality: A meta-analytic review. Health Psychology, 19, 211-222

${ }^{2}$ Powell, L.H., Shahabi, L. \& Thoresen, C.E. (2003). Religion and spirituality: Linkages to physical health. American Psychologist, 58, 53-63.

${ }^{3}$ Fontana, D. (2003). Psychology, religion, and spirituality. Leicester: BPS Blackwell

${ }^{4}$ Koenig. H., King, D. \& Carson, V.B. (2012). Handbook of Religion and Health. Oxford: Oxford University Press.

${ }^{5}$ Benor, D.J. (2000). Distant Healing. Subtle Energies, 11(3), 249-264.

${ }^{6}$ Dossey, L. (1993). Healing Words: The Power of Prayer and the Practice of Medicine. HarperSanFrancisco.

${ }^{7}$ Schouten, S. (1993). Applied parapsychology studies of psychics and healers. Journal of Scientific Exploration, 7, $375-401$.

${ }^{8}$ Solfvin, J. (1984). Mental healing. In S. Krippner (Ed.), Advances in parapsychological research, Vol. 4 (pp. 3163). Jefferson, NC: McFarland.

${ }^{9}$ Astin, J.A., Harkness, E., \& Ernst E. (2000). The Efficacy of "Distant Healing": A Systematic Review of Randomized Trials. Annals of Internal Medicine, 132, 903-910.

${ }^{10}$ Byrd, R.C. (1988). Positive Therapeutic Effects of Intercessory Prayer in a Coronary Care Unit Population. Southern Medical Journal, 81, 826-829. 
${ }^{11}$ Sicher, F., Targ, E., Moore, D., \& Smith, H. (1998). A randomized Double Blind Study of the Effect of Distant healing in a Population with Advanced AIDS: Report of a small scale study. Western Journal of Medicine, 169, 356-363.

${ }^{12}$ Bronson, P. (2002). A prayer before dying. Wired Magazine, 10(12) December. Available at http://www.wired.com/wired/archive/10.12/prayer.html

${ }^{13}$ Schmidt, S., Schneider, R., Utts, J., \& Walach, H. (2004). Distant intentionality and the feeling of being stared at: Two meta-analyses. British Journal of Psychology, 95, 235-247.

${ }^{14}$ Astin, J. A. (2003). Intercessionary prayer and healing prayer. In W.B. Jonas \& C.C. Crawford (Eds) Healing intention and energy medicine. pp. 13-22.

${ }^{15}$ Daley, B. (1997). Therapeutic touch, nursing practice and contemporary cutaneous wound healing research. Journal of Advanced Nursing, 25, 1123-1132.

${ }^{16}$ Ernst, E. (2003). Distant healing: An 'update' of a systematic review. Wien Klin Wochenschr, 115(7-8), 241-245.

${ }^{17}$ Braud, W. (2003). Distant mental influence: Its contributions to science, healing, and human interactions. Charlottesville, VA : Hampton Roads Pub.

${ }^{18}$ Jhaveri,A., Walsh,S.J., Wang, Y., McCarthy,M.B., Gronowicz, G. (2008). Therapeutic Touch Affects DNA Synthesis and Mineralization of Human Osteoblasts in Culture. Journal of Orthopaedic Research, 26, 15411546.

${ }^{19}$ Roney-Dougal, S.M. \& Solfvin, J. (2002). Field study of enhancement effect on lettuce seeds: Their germination rate, growth and health. Journal of the Society of Psychical Research, 66, 129-143.

${ }^{20}$ Roney-Dougal, S.M. \& Solfvin, J. (2003). Field study of an enhancement effect on lettuce seeds: Replication study. Journal of Parapsychology, 67(2), 279-298.

${ }^{21}$ Roney-Dougal, S.M. \& Solfvin, J.(2006). Field Study of an Enhancement Effect on Lettuce Seeds: Working in adverse conditions, Subtle Energies and Energy Medicine, 15(3), 183-207.

${ }^{22}$ Gronowicz, G.A., Jhaveri, A., Clarke L.W., Aronow, M.S., \& Smith, T.H. (2008). Therapeutic touch stimulates the proliferation of human cells in culture. Journal of Alternative and Complementary Medicine, 4(3), 233-239.

${ }^{23}$ Flamm, B. (2004). The Columbia University 'Miracle' Study: Flawed and Fraud. Skeptical Inquirer, 28.5.

${ }^{24}$ Solfvin, J., Leskowitz, E., \& Benor, D.J. (2005). Questions Concerning the Work of Daniel P. Wirth. The Journal of Alternative and Complementary Medicine, 11(6), 949-950.

${ }^{25}$ Krukoff, M.W., Crater, S.W., Green, C.L., Maas, A.C., Seskevich, J.E., Lane, J.D., Loeffler, K.A., Bashore, T.M., \& Koenig, H.G. (2001) Integrative noetic therapies as adjuncts to percutaneous intervention during unstable coronary syndromes: Monitoring and Actualization of Noetic Training (MANTRA) feasibility pilot. American Heart Journal, 142(5), 760-769.

${ }^{26}$ Leibovici, L. (2001). Effects of remote, retroactive intercessory prayer on outcomes in patients with bloodstream infection: randomised controlled trial. $B M J, \mathbf{3 2 3}, 1450-1451$. 
Two Meta-Analyses of Noncontact Healing Studies

${ }^{27}$ Aviles et al. (2001) Intercessory Prayer and Cardiovascular Disease Progression in a Coronary Care Unit Population: A Randomized Controlled Trial. Mayo Clinic Proceedings, 76, 1192-1198.

${ }^{28}$ Benson H., Dusek, J.A., Sherwood, J.B., et al. (2006). Study of the Therapeutic Effects of Intercessory Prayer (STEP) in cardiac bypass patients: A multicenter randomized trial of uncertainty and certainty of receiving intercessory prayer. American Heart Journal, 151(4), 934-42.

${ }^{29}$ Krukoff, M.W., Crater, S.W., Gallup, D., et al. (2005). Music, imagery, touch, and prayer as adjuncts to interventional cardiac care: the Monitoring and Actualisation of Noetic Trainings (MANTRA) II randomised study. The Lancet, 366, 211-17.

${ }^{30}$ Bösch, H., Steinkamp, F., \& Boller, E. (2006). Examining psychokinesis: The interaction of human intention with random number generators-A meta-analysis. Psychological Bulletin, 132, 497-523.

${ }^{31}$ Radin, D. I., \& Nelson, R. D. (2003). Research on mind-matter interactions (MMI): Individual intention. In W. B. Jonas \& C. C. Crawford (Eds.), Healing, intention and energy medicine: Science, research methods and clinical implications (pp. 39-48). Edinburgh: Churchill Livingstone.

${ }^{32}$ Braud, W. G., \& Schlitz, M. J. (1991) Consciousness interactions with remote biological systems: Anomalous intentionality effects. Subtle Energies, 2, 1-46.

${ }^{33}$ Field, T., Henteleff, T., Hernandez-Reif, M., Martinez, E., Mavunda, K., Kuhn, C., \& Schanberg, S. (1998). Children with asthma have Improved pulmonary function after massage treatment, Journal of Pediatrics, 132(5), 854-858.

${ }^{34}$ Hernandez-Reif, M., Dieter, J., Field, T., Swerdlow, B., \& Diego, M. (1998). Migraine headaches are reduced by massage therapy. International Journal of Neuroscience, 96, 1-11.

${ }^{35}$ Ironson, G., Field, T., Scafidi, F., Hashimoto, M., Kumar, M., Kumar, A., et al. (1996). Massage therapy is associated with enhancement of the immune system's cytotoxic capacity. Int J Neurosci., 84(1-4), 205-17.

${ }^{36}$ Scottish Intercollegiate Guidelines Network (2008). SIGN 50: A guideline developer's handbook. Available from http://www.sign.ac.uk/pdf/sign50.pdf

${ }^{37}$ Clark-Carter (2010). Quantitative psychological research: The complete student's companion (3rd ed.). Hove, England: Psychology Press.

${ }^{38}$ Jonas, W. (2001) The Middle Way: Realistic Randomized Controlled Trials for the Evaluation of Spiritual Healing. The Journal Of Alternative And Complementary Medicine, 7(1), 5-7.

${ }^{39}$ Rosenthal, R. (1979). The file drawer problem and tolerance of null results. Psychological Bulletin, 86, 638-641. 
Appendix 1: Non-whole human database

Bai, F., Sun, C., Liu Z, Shen, J., Shen, Y.G.R., Bei, C., Hang, J., Shi, Z., Liu, Y., \& Liu, X. (2000). Seeds induced to germinate rapidly by mentally projected 'qi energy' are apparently genetically altered. American Journal of Chinese Medicine, 28(1), 3-8.

Baldwin, A., \& Schwartz, G. (2006). Personal interaction with a reiki practitioner decreased noise induced microvascular damage in an animal model. The Journal of Alternative and Complementary Medicine, 12(1) 15-22.

Baldwin, A.L., Wagers, C., \& Schwartz, G.E. (2008). Reiki improves heart rate homeostasis in laboratory rats. The Journal of Alternative and Complementary Medicine, 14(4), 417-422.

Barrington, M.R. (1982). Bean growth promotion pilot experiment. Proceedings of the Society for Psychical Research, 56(212), 302-304.

Barry, J. (1968). General and comparative study of the psychokinetic effects on a fungus culture. Journal of Parapsychology, 32(4), 237-243.

Bengston, W.F., \& Krinsley D. (2000). The effect of the "laying on of hands" on transplanted breast cancer in mice Journal of Scientific Exploration, 14(3), 353-364.

Braud, W., Davis, G., \& Wood, R. (1979). Experiments with Matthew Manning. Journal of the Society For Psychical Research, 50(782), 199-223.

Braud, W.G. (2003). Mentally protecting human red blood cells at a distance. Distant Mental Influence. Charlottesville, VA: Hampton roads Publishing Company, Inc.

Bunnell, T. (1999). The effect of "healing with intent" on pepsin enzyme activity. Journal of Scientific Exploration, $13,139-148$.

Chen K., Shiflett S., Ponzio N., He, B., Elliott, D., \& Keller, S. (2002). A preliminary study of the effect of external qigong on lymphoma growth in mice. The Journal of Alternative and Complementary Medicine, 8(5), 615621.

Creath, K., \& Schwartz G.E. (2004). Measuring effects of music noise and healing energy using a seed germination bioassay. The Journal of Alternative and Complementary Medicine, 10(1), 113-122.

Denburg, J.L., Burgess, P.R., Hughes, R.W., \& Southwood, M.S. (nd). Alteration of growth of cultured neurons by the conscious intention of an energy healer Unpublished manuscript retrieved from http://www.southwoodhealing.info/p_d_f/scientificpaper/pdf on05/04/2011

Gronowicz G.A., Jhaveri, A., Clarke L.W., Aronow, M.S., \& Smith, T.H. (2008). Therapeutic touch stimulates the proliferation of human cells in culture. The Journal of Alternative and Complementary Medicine, 14(3), 233239.

Hall, Z., Luu, T., Moore, D., \& Yount, G. (2006). Radiation response of cultured human cells is unaffected by johrei. Ecam, 4(2), $191-194$. 
Two Meta-Analyses of Noncontact Healing Studies

Haraldsson, E., \& Thorsteinsson, T. (1973). Psychokinetic effects on yeast: An exploratory experiment. In W.G. Roll, R.L. Morris, \& J.D. Morris (Eds) Research in Parapsychology 1972. (pp. 20-21).

Harkness, E., Abbot, N., \& Ernst, E. (2000). A randomized trial of distant healing for skin warts. The American Journal of Medicine, 108, 448-452.

Jahveri, A., Walsh, S.J., Wang, Y., Mccarthy, M., \& Gronowicz, G. (2008). Therapeutic touch affects DNA synthesis and mineralization of human osteoblasts in culture. Journal of Orthopaedic Research, 26, 15411546.

Kiang, J.G., Marotta, D., Wirkus, M., \& Jonas, W.B.(2002). External bio energy increases intercellular free calcium concentration and reduces cellular response to heat stress. Journal of Investigative Medicine, 50(1), 38-45.

Lee, M., Jeong, S.M., Jang, H.S., Ryu, H., \& Moon, S.R. (2003). Effects of in vitro and in vivo qi-therapy on neutrophil superoxide generation in healthy male subjects. American Journal of Chinese Medicine, 31(4), $623-628$.

Lei, X.F., Bi, A.H., Zhang, Z.X., \& Chen, Z.Y. (1991). The antitumor effects of qi gong-emitted external qi and its influence on the immunologic functions of tumour-bearing mice. Journal of Tongli Medical University, 11(4), 253-256.

Lenington, S. (1979). Effect of holy water on the growth of radish plants. Psychological Reports, 45(2), 381-382.

Lesniak, K.T. (2006). The effect of intercessory prayer on wound healing in non-human primates. Alternative Therapies in Health and Medicine, 12(6), 42-48.

Macdonald, R.G., Hickman, J.L., \& Dakin, H.S. (1977). Preliminary psychical effects associated with three alleged psychic healers. In J.D. Morris, W.G. Roll \& R.L. Morris (Eds) Research in Parapsychology 1976, Metuchen, NJ: Scarecrow Press. (pp. 74-76).

Nash, C.B. (1984). Test of psychokinetic control of bacterial mutation. Journal of the American Society for Psychical Research, 78(2), 145-152.

Nash, C.B. (1982). Psychokinetic control of bacterial growth. Journal of the Society for Psychical Research, 51(790), 217-221.

Radin, D., Taft, R., \& Yount, G. (2004). Effects of healing intention on cultured cells and truly random events. The Journal of Alternative and Complementary Medicine, 10(1), 103-112.

Roney-Dougal, S., \& Solfvin, J. (2002). Field study of an enhancement effect on lettuce seeds: Their germination rate growth and health. Journal of the Society for Psychical Research, 66(868), 129-143.

Roney-Dougal, S., \& Solfvin, J. (2004). Field study of an enhancement effect on lettuce seeds: Working in adverse condition. Proceedings of Presented Papers: The Parapsychological Association Convention 2004 proceedings of presented papers

Roney-Dougal, S, \& Solfvin, J. (2003). Field study of an enhancement effect on lettuce seeds: A replication. Journal of Parapsychology, 67(2), 279. 
Rubik, B., Brooks, A., \& Schwartz, G. (2006). In vitro effect of reek treatment on bacterial cultures: Role of experimental context and practitioner well-being. The Journal of Alternative and Complementary Medicine, 12(1), 7-13.

Saklani, A. (1988). Preliminary tests for psi-ability in shamans of Garhwali Himalaya. Journal of the Society for Psychical Research, 55(811), 60-70.

Saklani, A. (1990). Psychokinetic effects on plant growth: Further studies. In L:.A. Henkel \& J. Palmer (Eds) Research in Parapsychology 1989. Metuchen, NJ: Scarecrow Press. (pp. 37-41).

Schofield, A.M., \& Hodges, R. (1991). Demonstration of a healing effect in the laboratory using a simple plant model. Journal of the Society for Psychical Research, 57(822), 321-343.

Shah S., Ogden, A.T., Pettker, C.M., Raffo, A., Itescu, S., \& Oz, M.C. (1999). A study of the effect of energy healing on in vitro tumour cell proliferation. The Journal of Alternative and Complementary Medicine, 5(4), 359-365.

Smith, A.L., \& Laskow, L. (2000). Intentional healing in cultured breast cancer cells. Proceedings of the Academy of Religion and Psychical Research Annual Conference. Sourced from http://www.laskow.net/resources.shtml on $21 / 03 / 2011$

Snel, F. (1980). PK influence on malignant cell growth. Research Letter of the University of Utrecht, 10, 19-27.

Snel, F.W.J., \& Van der Sijde, P.C (1995). The effect of paranormal healing on tumour growth. Journalof Scientific Exploration, 9(2), 209-221.

Snel, F., \& Holt, P.R. (1983). Psychokinesis experiments in casein induced amyloidosis of the hamster. European Journal of Parapsychology, 5, 51-79.

Solfvin, G.F. (1982). Studies of the effects of mental healing and expectations on the growth of corn seedlings.

European Journal of Parapsychology, 4, 287-323.

Strickland, M.L., \& Boylan, H.M. (2010). Using enzyme folding to explore the mechanism of therapeutic touch: A feasibility study. The Journal of Alternative and Complementary Medicine, 16(7), 715-721.

Taft, R., Luz, N., Tri, L., Pennucci, A., Moore, D., \& Yount, G. (2005). Cultured human brain tumour cells do not respond to Johrei treatment. Subtle Energies and Energy Medicine, 14(3), 253-265.

Taft, R., Moore, D., \& Yount, G. (2005). Time lapsed analysis of potential cellular responsiveness to Johrei, a Japanese healing technique. BMC Complementary and Alternative Medicine, 5, 2.

Tedder, W.H., \& Monty, M.L. (1981). Exploration of long-distance PK: A conceptual replication of the influence on a biological system. In W.G. Roll \& J. Beloff (Eds) Research in Parapsychology 1980. Metuchen, NJ: Scarecrow Press. (pp. 90-93).

Teixeira, P.C.N., Rocha, H., \& Nelto, J.A.C. (2010). Johrei, a Japanese healing technique, enhances the growth of sucrose crystals. Explore, 6(5), 313-323. 
Two Meta-Analyses of Noncontact Healing Studies

Watkins, G.K., Watkins, A.M., \& Wells, R.A. (1973). Further studies of the resuscitation of anesthetized mice. In W.G. Roll, R.L. Morris, \& J.D. Morris (Eds) Research in Parapsychology 1972. (pp. 157-159).

Wells, R., \& Kelin, J. (1972). A replication of a "psychic healing" paradigm. Journal of Parapsychology, 36, 144149.

Yount, G., Solfvin, J., Moore, D., Schlitz, M., Reading, M., Aldape, K., \& Qian, Y. (2004). In vitro test of external qigong. BMC Complementary and Alternative Medicine, 4, 5.

Yu, T., Tsai, H.L., \& Hwag, M.L. (2003). Suppressing tumour progression of in vitro prostate cancer cells by emitted psychosomatic power through Zen meditation. The American Journal of Chinese Medicine, 21(3), $499-507$.

Zachariae, R., Højgaard, L., Zavahriae, C., Væth, M., Bang, B., \& Skov, L. (2005). The effect of spiritual healing on in vitro tumour cell proliferation and viability- an experimental study. British Journal of Cancer, 93, 538-543.

Appendix 2: Whole human database

Abbot, N.C., Harkness, E.F., Stevinson, C., Marshall, F.P., Conn, D.A., \& Ernst, E. (2001). Spiritual healing as a therapy for chronic pain: A randomized clinical trial. Pain, 91, 79-89.

Aghabati, N., Mohamadi, E., \& Esmaiel, Z.P. (2008). The effect of therapeutic touch on pain and fatigue of cancer patients undergoing chemotherapy. Ecam, 7(3), 375-381.

Assefi, N., Bogart, A., Goldberg, J., \& Buchwald, D. (2008). Reiki for the treatment of fibromyalgia: A randomized controlled trial. The Journal of Alternative and Complementary Medicine, 14(9), 1115-1122.

Aviles, J.M., Whelan, S.E., Hernke, D.A., Brent, A.W., Kenny, K.E. ,O'Fallon, M., \& Kopecky, S.L. (2001). Intercessory prayer and cardiovascular disease progression in a coronary care unit population: A randomized controlled trial. Mayo Clinic Proceedings, 76(12), 1192-1198.

Barlow, F., Lewith, G.T., \& Walker, J. (2008). Experience of proximate spiritual healing in women with breast cancer, who are receiving long-term hormonal therapy. The Journal of Alternative and Complementary Medicine, 14(3), 227-231.

Benson , H. et al. (2006). Study of the therapeutic effects of intercessory prayer (step) in cardiac bypass patients: A multicentre randomized trial of uncertainty and certainty of receiving intercessory prayer. American Heart Journal, 151(4), 934-942.

Beutler, J.J., Attevelt, J.T.M., Schouten, S.A., Faber, J.A.J, Dorhout Mees, E.J., \& Geijskes, G.G. (1988). Paranormal healing and hypertension. British Medical Journal, 296, 1491-1494.

Bowden, D., Goddard, L., \& Gruzelier, J. (2011). A randomized controlled single-blind trial of the efficacy of Reiki at benefitting mood and well-being. Evidence Based Complementary and Alternative Medicine, Vol 2011, doi:10.1155/2011/381862.

Bowden, D., Goddard, L., \& Gruzelier, J. (2010). A randomised controlled single-blind trial of the effects of Reiki and positive imagery on well-being and salivary cortisol. Brain Research Bulletin, 81(1), 66-72. 
Brooks, A., Schwartz, G.E., Reece, K., \& Nagle, G. (2006). The effect of Johrei healing on substance abuse recovery: A pilot study. The Journal of Alternative and Complementary Medicine, 12(7), 625-631.

Brown, C.K. (1995). Spiritual healing in a general practice: Using a quality-of-life questionnaire to measure outcome. Complementary Therapies in Medicine, 3(4), 230-233.

Bunnell, T. (2002). The effect of "healing with intent" on peak expiratory flow rates in asthmatics. International Journal of Subtle Energies And Energy Medicine, 13(1), 75-89.

Byrd, R. (1988). Positive therapeutic effects of intercessory prayer in a coronary care unit population. Southern Medical Journal, 81(7), 826-829.

Chen, K.W., Afton, H.L., Hou, F., Staller, J., \& Lichtbroun, A.S. (2006). A pilot study of external qigong therapy for patients with fibromyalgia. The Journal of Alternative and Complementary Medicine, 12(9), 851-856.

Clenad, J.A., Price, D.B., Lee, A.J., Gerard, S., \& Sarma, A. (2006). A pragmatic, three arm randomised controlled trial of spiritual healing for asthma in primary care. British Journal of General Practice, 56(527), 444-449.

Conti, J.M., Matthews, W.J., \& Sireci, S.C. (2003). Intercessory prayer, visualisation and expectancy for patients with severe illness implications for psychotherapy. Annals of American Psychotherapy, 16, 20-27.

Cox, C., \& Hayes, J. (1999). Physiologic and psychodynamic responses to the administration of therapeutic touch in critical care. Intensive and Critical Care Nursing, 15, 363-368.

DaSilva, F.E., et al. (2008). Distant healing intention to autistic patients: An exploratory study. 4th Psi Meeting:

Parapsychology and Psychology. Retrieved from http://www.unibem.br/cipe/3_links_pdf/Link_09_Distant_healing_intention_to_autistic_patients.pdf accessed $17 / 06 / 2011$

Dennison, B. (2004). Touch the pain away: New research on therapeutic touch and persons with fibromyalgia syndrome. Holistic Nursing Practice, 8(3), 142-151.

Dixon, M. (1998). Does 'healing' benefit patients with chronic symptoms? A quasi-randomized trial in general practice. Journal of The Royal Society of Medicine, 91, 183-188.

Engle, V.F., \& Graney, M.J. (2000). Biobehavioural effects of therapeutic touch. Journal of Nursing Scholarship, 32(3), 287-293.

Gerard, S., Smith, B.H., \& Simpson, J.A. (2003). A randomized controlled trial of spiritual healing in restricted neck movement. The Journal of Alternative and Complementary Medicine, 9(4), 467-477.

Giasson, M., \& Bouchard, L. (1998). Effect of therapeutic touch on the well being of persons with terminal cancer. Journal of Holistic Nursing, 16(3), 383-398.

Gordon, A., Merenstein, J., D'amico, F., \& Hodges, D. (1998). The effects of therapeutic touch on patients with osteoarthritis of the knee. The Journal of Family Practice, 47(4), 271-277.

Greyson, B. (1996). Distance healing of patients with major depression. Journal of Scientific Exploration, 10(4), 447-465. 
Two Meta-Analyses of Noncontact Healing Studies

Hagemaster, J. (2000). Use of therapeutic touch in treatment of drug addictions. Holistic Nursing Practice, 14(30), $14-20$.

Harris, W.S., Gowda, M., Kolb, J.W., Strychacz, C.P., Vacek, J.L., Jones, P.G., Forker, A., O'Keefe, J.H., \& Mccallister B.D. (1999). A randomized, controlled trial of the effects of remote intercessory prayer in outcomes in patients admitted to the coronary care unit. Archives of Internal Medicine, 159(19), 2273-2278.

Hawranik, P., Johnston, P., \& Deatrich. J. (2008). Therapeutic touch and agitation in individuals with alzheimer's disease. Western Journal of Nursing Research, 30(4), 417-434.

Ireland, M. (1998). Therapeutic touch with hiv infected children: A pilot study. Journal of the Association of Nurses in Aids Care, 9(4), 68-77.

Jang, H.S., \& Lee, M.S. (2004). Effects of qi therapy (external qigong) on premenstrual syndrome: A randomized placebo controlled study. The Journal of Alternative and Complementary Medicine, 10(3), 456- 462.

Joyce, C.R.B., \& Welldon, R.M.C. (1965). The objective efficacy of prayer: A double blind clinical trial. Journal of Chronic Diseases, 18(4), 637-677.

Keller, E., \& Bzdek, V.M. (1986). Effects of therapeutic touch on tension headache pain. Nursing Research, 35(2), 101-106.

Krieger, D. (1972). The response of invivo hemoglobin to an active therapy by direct laying on of hands. Human Dimensions, 1, 12-15.

Krucoff, M.W., et al. (2001). Integrative noetic therapies as adjuncts to percutaneous interventions during unstable coronary syndromes; Monitoring and actualization of noetic training (mantra) feasibility pilot. American Heart Journal, 42(5), 760-769.

Krucoff, M.W., et al. (2005). Music, imagery, touch and prayer as adjuncts to interventional cardiac care: The monitoring and actualisation of noetic trainings (mantra) ii randomised study. The Lancet, 366(9481), 211217.

Lafreniere, K., Mutus, B., Cameron, S., Tannous, M., Gianotti, M., Abu-Zahra, H., \& Laukkanen, E. (1999). Effects of therapeutic touch on biochemical and mood indicators in women. The Journal of Alternative and Complementary Medicine, 5(4), 367-370.

Laidlaw, T.M., Naito, A., Dwivedi, P., Hansi, N.K., Henderson, D.C., \& Gruzelier, J.H. (2006). The influence of 10 minutes of the Johrei healing method on stress. Complementary Therapies in Medicine, 14(2), 127-132.

Larden, C.N., Palmer, L., \& Janssen, P. (2004). Efficacy of therapeutic touch in treating pregnant inpatients who have a chemical dependency. Journal of Holistic Nursing, 22(4), 320-332.

Le Gallez, P., Dimmock, S., \& Bird, H.A. (2000). Spirtitual healing as adjunct therapy of rheumatoid arthritis. British Journal of Nursing, 9(11), 395-700. 
Lee, M.S., Huh, H.J., Hong, S.S., Jang, H.S., Ryu, H., Lee, H.S., \& Chung, H.T. (2001). Psychoneuroimmunological effects of qi therapy: Preliminary study on the changes of level of anxiety, mood, cortisol and melatonin and cellular function of neutrophil and natural killer cells. Stress and Health, 17(1), 17-24.

Lee. M.S., Jang, J.W., Jang, H.S., \& Moon, S.R. (2003). Effects of qi- therapy on blood pressure, pain and psychological symptoms in the elderly: A randomized controlled pilot trail. Complementary Therapies in Medicine, 11(3), 159-164.

Lin, Y.S., \& Taylor, A.G. (1998). Effects of therapeutic touch in reducing pain and anxiety in an elderly population. Integrative Medicine, 1(4), 152-162.

Loveland Cook, C.A., Guerrerio, J.F., \& Slater, V.E. (2004). Healing touch and quality of life in women receiving radiation treatment for cancer: A randomized controlled trial. Alternative Therapies, 10(3), 34-41.

Mackay, N., Hansen, S., \& Mcfarlane, O. (2004). Autonomic nervous system changes during Reiki treatment: A preliminary study. Journal of Alternative and Complementary Medicine, 10(6), 1077-1081.

Mathai, J., \& Bourne, A. (2004). Pilot study investigating the effect of intercessory prayer in the treatment of child psychiatric disorders. Australasian Psychiatry, 12(4), 386-389.

Mccormack, G.L. (2009). Using non-contact therapeutic touch to manage post-surgical pain in the elderly. Occupational Therapy International, 16(1), 44-56.

Meehan, T.C. (1993). Therapeutic touch and postoperative pain: A rogerian research study. Nursing Science Quarterly, 6(2), 69-77.

Miller, R. (1982). Study on the effectiveness of remote mental healing. Medical Hypothesis, 8(5), 481-490.

Olson, M., Sneed, N., Bonadonna, R., Ratliff, J., \& Dias, J. (1992). Therapeutic touch and post Hurricane Hugo stress. Journal of Holistic Nursing, 10(2), 120-136.

Olson, M., Sneed, N., Lavia, M., Virelle, G., Bonadonna, R., \& Michel, Y. (1997). Stress induced immunosuppression and therapeutic touch. Alternative Therapies, 3(2), 68-74.

Peck, S.D. (1998). The efficacy of therapeutic touch for improving functional ability in elders with degenerative arthritis. Nursing Science Quarterly, 11(3), 123-132.

Quinn, J.F. (1988). Therapeutic touch as energy exchange: Replication and extension. Nursing Science Quarterly, 2(2), 79-87.

Radin, D.I., Machado, F.R., \& Zangari, W. (2000). Effects of distant healing intention through time and space: Two exploratory studies. Subtle Energies and Energy Medicine, 11(3), 207-239.

Reece, K., Schwartz, G.E., Brooks, A.J. ,\& Nangle, G. (2005). Positive well-being changes associated with giving and receiving Johrei healing. The Journal of Alternative and Complementary Medicine, 11(3), 455-457.

Richeson, N.E., Spross, J.A., Lutz, K., \& Peng, C. (2010). Effects of Reiki on anxiety depression pain and physiological factors in community-dwelling older adults. Research in Gerontological Nursing, 3(3), 187199. 
Samarel, N., Fawcett, J., Davis, M.M., \& Ryan, F. (1998). Effects of dialogue and therapeutic touch on preoperative and p[ostoperative experiences of breast cancer surgery: An exploratory study. Oncology Nursing Forum, 25(8), 1369-1376.

Shore, A.G. (2004). Long term effects of energetic healing on symptoms of psychological depression and selfperceived stress. Alternative Therapies, 10(3), 42-48.

Sicher, F., Targ, E., Moore, D., \& Smith , H.S. (1998). A randomized double-blind study of the effects of distant healing in a population with advanced aids report of a small scale study. Western Journal of Medicine, 169(6), 356-363.

Smith-Frank, L., Frank, J.L., March, D., Makari-Judson, G., Barham, R. B., \& Mertens, W.C. (2007). Does therapeutic touch ease the discomfort or distress in patients undergoing stereotactic core breast biopsy? A randomized clinical trial. Pain Medicine, 8(5), 419-424.

Sundblom, D. M., Haikonen, S., Niemi-Pynttari, J., \& Tigerstedt, I. (1994). Effect of spiritual healing on chronic idiopathic pain: A medical and psychological study. The Clinical Journal of Pain, 10(4), 296-302.

Tsubono, K., Thomlinson, P., \& Shealy, N. (2009). The effects of distant healing performed by a spiritual healer on chronic pain: A randomised controlled trial. Alternative Therapies, 15(3), 30-34.

Turner, J.G., Clark, A.J., Gauthier, D.K., \& Williams, M. (1998). The effect of therapeutic touch on pain and anxiety in burn patients. Journal of Advanced Nursing, 28(1), 10-20.

Vannemreddy, P., Bryan, K., \& Nanda, A. (2009). Influence of prayer and prayer habits in outcome in patients with severe head injury. American Journal of Hospice and Palliative Medicine, 26(4), 264-269.

Vuckovic, N.H., Gullion, C.M, Williams, L.A, Ramirex, M, \& Schneider, J. (2007). Feasibility and short-term outcomes of a shamanic treatment for temporomandibular joint disorders. Alternative Therapies, 13(6), 18-29.

Walker, S.R., Tonigan, J.S., Miller, W.R., Comer, S., \& Kahlich, L. (1997). Intercessory prayer in the treatment of alcohol abuse and dependence: A pilot investigation. Alternative Therapies, 3(6), 79-86.

Walach, H., et al. (2008). Effectiveness of distant healing for patients with chronic fatigue syndrome: A randomised controlled partially blinded trial (EUHEALS). Psychotherapy and Psychosomatics, 77(3), 158-166.

Whitley, J., \& Rich, B.L. (2008). A double-blind randomized controlled pilot trial examining the safety and efficacy of therapeutic touch in premature infants. Advances in Neo-Natal Care, 8(6), 315-333.

Woods-Smith, D., Arnstein, P., Cowen-Rosa, C., \& Wells-Federman, C. (2002). Effects of integrating therapeutic touch into a cognitive behavioural pain treatment programme: Report of a pilot clinical trial. Journal of Holistic Nursing, 20(4), 367-387.

Zare, Z., Shahsavari, H., \& Moeini, M. (2009). Effects of therapeutic touch on the vital signs of patients before coronary artery bypass graft surgery. Iranian Journal of Nursing and Midwifery, 15(1), 32-37. 